\title{
Virulence factors of fluconazole-susceptible and fluconazole-resistant Candida albicans after antimicrobial photodynamic therapy
}

\author{
Fernanda Alves ${ }^{1} \cdot$ Ewerton Garcia de Oliveira Mima ${ }^{1}$. \\ Renata Caroline Polato Passador ${ }^{1}$ - Vanderlei Salvador Bagnato ${ }^{2}$. \\ Janaína Habib Jorge $^{1}$ • Ana Cláudia Pavarina ${ }^{1}$
}

Received: 22 September 2016 / Accepted: 20 February 2017 /Published online: 9 March 2017

(C) Springer-Verlag London 2017

\begin{abstract}
This study evaluated the effects of antimicrobial photodynamic therapy (aPDT) mediated by Photodithazine ${ }^{\circledR}$ (PDZ) and LED light on the virulence factors of fluconazolesusceptible $(\mathrm{CaS})$ and fluconazole-resistant $(\mathrm{CaR})$ Candida albicans. Standardized suspensions of strains were prepared $\left(10^{7}\right)$, and after $48 \mathrm{~h}$ of biofilm formation, these strains were incubated with PDZ $(100 \mathrm{mg} / \mathrm{L})$ for $20 \mathrm{~min}$ and exposed to LED light $\left(660 \mathrm{~nm}, 37.5 \mathrm{~J} / \mathrm{cm}^{2}\right)$. Additional samples were treated with PDZ or light only, and the control consisted of biofilms that received no treatment. After aPDT, the cells were recovered and the virulence factors were evaluated. To analyze the capacity of adhesion, cells were recovered after aPDT and submitted to the adhesion process in the bottom of a 96well plate. After this, metabolic activity tests (XTT assay) and cell viability (colony forming units per milliliter, $\mathrm{CFU} / \mathrm{mL}$ ) were applied. To evaluate the biofilm-forming ability after aPDT, the cells recovered were submitted to biofilm formation procedures, and the biofilm formed was evaluated by XTT, $\mathrm{CFU} / \mathrm{mL}$, and total biomass (crystal violet) tests. Lastly, the capacity for synthesizing protease and phospholipase enzymes after aPDT was evaluated by fluorimetric tests. Data were analyzed by two- or three-way ANOVA tests $(p \leq 0.05)$. It was verified that aPDT reduced the viability of both strains, fluconazole-susceptible and fluconazole-resistant $C$. albicans. It was also observed that the CaR strain had lower
\end{abstract}

Ana Cláudia Pavarina pavarina@foar.unesp.br

1 Department of Dental Materials and Prosthodontics, Araraquara Dental School, UNESP - Univ. Estadual Paulista, Rua Humaitá, 1680, 14801-903 Araraquara, SP, Brazil

2 Biophotonics Lab, Group of Optics, Physics Institute of São Carlos, University of São Paulo - USP, Av. Trabalhador São-carlense, 400, 13566-590 São Carlos, SP, Brazil susceptibility to the aPDT when compared with the CaS strain. However, regarding the virulence factors evaluated, it was demonstrated that aPDT did not alter the adherence and biofilm formation ability and enzymatic production.

Keywords Candida albicans · Photodynamic inactivation · Drug resistance $\cdot$ Virulence factors

\section{Introduction}

Candida albicans is commonly found in human beings in a relationship of commensalism; however, when there is imbalance in the host immune system, this fungus may invade tissues and cause superficial infections such as oropharyngeal candidosis (OPC) [1]. The pathogenesis of OPC may be related to the host conditions and virulence of the microorganism [2]. Diabetic patients, users of immunosuppressive medications and broad-spectrum antibiotics, individuals submitted to antineoplastic therapies, and AIDS patients present a high incidence of infection by Candida [3].

Moreover, C. albicans presents virulence factors that aid the colonization and invasion of host tissues [4]. Organization into biofilms may be considered an important virulence factor [5] since it is intimately associated with the capacity to cause infections, protect development of the microorganism in hostile environments, and prevent the penetration of antifungal drugs [5]. Furthermore, the production of enzymes, such as proteinases and phospholipases, plays an important role in the pathogenicity of these fungi since these enzymes are able to hydrolyze important phospholipids and proteins of the cytoplasmic membrane of the host cell, resulting in the rupture of this organelle $[6,7]$. 
Topical and systemic antifungal agents (polyenes and azoles, such as amphotericin B and itraconazole) have been used in the treatment of OPC; however, these medications may promote the development of hepatotoxicity and antifungal resistance [8]. Prophylactic treatment with fluconazole, recommended for HIV-positive patients, has been shown to cause substitution of susceptible $C$. albicans strains by those resistant to fluconazole [9]. Moreover, the fungistatic activity of azoles has also been associated with failure of antifungal treatment in immunocompromised patients. Another aspect related to antifungal resistance and recurrence of infection is the capacity of Candida spp. to form biofilms on surfaces [10, 11].

Due to the antifungal resistance and difficulties associated with the use of conventional medications, antimicrobial photodynamic therapy (aPDT) has been suggested for inactivating Candida spp. and for the treatment of superficial fungal infections [12-14]. Photodithazine ${ }^{\circledR}$ (PDZ), a second-generation photosensitizer (PS) derived from chlorine, has been successfully applied with aPDT against cancer [15]. In vitro studies have indicated that aPDT mediated by PDZ was effective in inactivating bacteria and fungi. Dovigo et al. [16] observed high rates of reduction in the metabolic activity of biofilms formed from clinical isolates of C. albicans, Candida tropicalis, and Candida glabrata after exposure to aPDT. Significant reduction in metabolic activity and cell viability has also been observed in multispecies biofilms [17].

Studies have demonstrated that the species of Candida present susceptibility to aPDT [12]; however, there are still some aspects that need to be clarified. Due to non-specific oxidant agents, the organisms resistant to conventional antifungal agents may be inactivated by aPDT. However, it has been verified that fluconazole-resistant strains of $C$. albicans and C. glabrata exhibit reduced sensitivity to aPDT compared to fluconazole-sensitive reference strains (ATCC), suggesting that the mechanisms of resistance of microorganisms to traditional antifungal medications may reduce the efficacy of aPDT [13]. In addition, the response of strains to aPDT has not been homogeneous among the resistant strains of the same species [13, 18]. Since the most promising advantage of aPDT would be to treat infections resistant to antifungal agents, the susceptibility of fluconazole-resistant $C$. albicans needs to be better understood. Moreover, both the action of aPDT mediated by PDZ against fluconazole-resistant $C$. albicans and the effect of aPDT on the virulence factors of fluconazole-susceptible and fluconazole-resistant $C$. albicans are unknown.

Therefore, the aim of this study was to evaluate the expression of virulence factors of fluconazole-susceptible and fluconazole-resistant $C$. albicans after aPDT mediated by PDZ associated with LED light. The virulence factors evaluated were as follows: capacity of adhesion and biofilm formation and the capacity for specific degradative enzyme synthesis (protease and phospholipase).

\section{Materials and methods}

\section{Photosensitizer and light source}

Photodithazine ${ }^{\circledR}$ (PDZ; VETA GRAND Co., Moscow, Russia), a chlorin e6 derivative, was used as PS. PDZ was diluted in physiological solution $(0.85 \% \mathrm{NaCl})$ in a concentration of $100 \mathrm{mg} / \mathrm{L}$. The PS was excited by a light-emitting diode (LED) in the red region of the spectrum $(660 \mathrm{~nm})$. This device is composed of red LEDs (LXHL-PR09, Luxeon® III Emitter, Lumileds Lighting, San Jose, CA, USA) uniformly distributed, with a constant power output of $71 \mathrm{~mW} / \mathrm{cm}^{2}$. The dose of light evaluated was $37.5 \mathrm{~J} / \mathrm{cm}^{2}$.

\section{Obtaining the biofilms and performing antimicrobial photodynamic therapy}

The standard strains of $C$. albicans ATCC 90028 (fluconazole-susceptible, CaS) and C. albicans ATCC 96901 (fluconazole-resistant, $\mathrm{CaR}$ ) were used to form biofilm. The strains were defrosted and reactivated in Sabouraud dextrose agar (SDA; Acumedia Manufacturers, Inc., Baltimore, MD, USA) culture medium containing $5 \mu \mathrm{g} / \mathrm{mL}$ of gentamicin and incubated $\left(37^{\circ} \mathrm{C} / 48 \mathrm{~h}\right)$. After this period, the cell cultures were inoculated in $5 \mathrm{~mL}$ of RPMI 1640 (Sigma-Aldrich, St. Louis, MO, USA) and incubated at $37^{\circ} \mathrm{C}$ for $16 \mathrm{~h}$ at $75 \mathrm{rpm}$ in an orbital agitator (AP 56, Phoenix Ind Com Equipamentos Científicos Ltda, Araraquara, SP, Brazil). After incubation, the cells were submitted to the steps for biofilm formation, described by Dovigo et al. [16]. In summary, the cells were washed and resuspended in phosphate-buffered saline (PBS). Cell concentration was adjusted to $10^{7}$ cells $/ \mathrm{mL}$ in a spectrophotometer $(540 \mathrm{~nm})$, and $100 \mu \mathrm{L}$ of this suspension was transferred to a 96-well plate. The plate was incubated at $37{ }^{\circ} \mathrm{C}$ for $1.5 \mathrm{~h}$ in an incubator shaker at $75 \mathrm{rpm}$ (adhesion stage). After this period, RPMI 1640 was added and the plate was incubated at $37{ }^{\circ} \mathrm{C}$ at $75 \mathrm{rpm}$ for $48 \mathrm{~h}$ (biofilm maturation).

After biofilm formation, the culture medium was removed and the biofilm was washed twice with PBS. To perform the aPDT, $100 \mu \mathrm{L}$ of PDZ was added to each biofilm. After this, the plates were incubated in the dark for $20 \mathrm{~min}$ (preirradiation time) and then illuminated with LED light for $9 \min \left(37.5 \mathrm{~J} / \mathrm{cm}^{2}\right.$; groups $\mathrm{P}+\mathrm{L}+\mathrm{CaS}$ and $\left.\mathrm{P}+\mathrm{L}+\mathrm{CaR}\right)$. Additional samples were treated with $\mathrm{PDZ}(\mathrm{P}+\mathrm{L}-\mathrm{CaS}$ or $\mathrm{P}+$ $\mathrm{L}-\mathrm{CaR})$ only or with LED light only $(\mathrm{P}-\mathrm{L}+\mathrm{CaS}$ and $\mathrm{P}-\mathrm{L}+$ $\mathrm{CaR})$. The control group received no treatment with $\mathrm{PDZ}$ or with LED light $(\mathrm{P}-\mathrm{L}-\mathrm{CaS}$ and $\mathrm{P}-\mathrm{L}-\mathrm{CaR})$.

After application of the treatments, tests were performed to evaluate the effectiveness of aPDT and its effect on the virulence factors. All the tests were performed in triplicate on three different occasions. It is important to point out that for each test and occasion performed, individual plates were used. 
Therefore, the evaluations were made directly on the cells coming from the biofilms that were submitted to the treatments described, according to the flow sheet (Fig. 1).

\section{Evaluation immediately after treatments}

To evaluate the efficacy of aPDT against the biofilms, the following methods were used: quantification of colonies (CFU/mL), evaluation of cell metabolism (XTT assay), and total biomass.

For quantifying the colonies $(\mathrm{CFU} / \mathrm{mL})$, on conclusion of treatments, the biofilms were detached from the wells with the aid of a sterile swab (Johnson \& Johnson, Nova Odessa, Brazil) and aliquots of $25 \mu \mathrm{L}$ of the serial dilution were plated on SDA medium. After incubation at $37^{\circ} \mathrm{C}$ for $48 \mathrm{~h}$, colony forming units per milliliter $(\mathrm{CFU} / \mathrm{mL})$ values were determined and transformed into $\log _{10}[16]$.

Biofilm cell metabolism was evaluated by means of the yellow tetrazolium salt XTT ( $\{2,3$-bis(2-methoxy-4nitro-5-sulfophenyl)-5-[(phenylamino)carbonyl]-2H tetrazolium hydroxide\}) reduction assay. For this purpose, after application of the treatments, $200 \mu \mathrm{L}$ of XTT solution (containing $158 \mu \mathrm{L}$ of PBS with the addition of $200 \mathrm{mM}$ glucose, $40 \mu \mathrm{L}$ of XTT, and $2 \mu \mathrm{L}$ of menadione) was added to each well. The plates were incubated at $37{ }^{\circ} \mathrm{C}$ in the dark for $3 \mathrm{~h}$ and colorimetrically measured in a microplate reader (Thermo Plate/TP Reader) at $492 \mathrm{~nm}[19]$.

The total biomass of biofilm was quantified by means of crystal violet (CV) staining. After being submitted to treatments, the biofilms were washed with PBS and then fixed with $200 \mu \mathrm{L}$ of methanol for $15 \mathrm{~min}$. The methanol was removed and the plates were kept at $37{ }^{\circ} \mathrm{C}$ for $20 \mathrm{~min}$ to dry. Subsequently, $200 \mu \mathrm{L}$ of CV $(1 \%, v / v)$ was added and maintained for $5 \mathrm{~min}$. The wells were washed with ultrapure water, and after this, $33 \%$ acetic acid was added to remove the dye. The result of this solubility was measured using the microplate reader at $570 \mathrm{~nm}[19]$.

\section{Evaluation of virulence factors}

Additional biofilms that received the previously described treatments were evaluated with regard to the following virulence factors: capacity for adhesion to abiotic surfaces, biofilm-forming capacity, and capacity for specific degradative enzyme synthesis (proteinase and phospholipase).

To evaluate the capacity for adhesion to abiotic surface, the treated biofilms were detached from the bottom of the wells; the cells were transferred to a new 96-well plate and submitted to the steps described previously for adhesion of the cells, as reported by Dovigo et al. [16]. After the adhesion stage, the adhered cells were evaluated according to the following previously described methods: quantification of colonies (CFU/ $\mathrm{mL}$ ) and cell metabolism (XTT assay). The values obtained after adhesion were statistically compared with those obtained from biofilms immediately after aPDT.

To evaluate the biofilm-forming capacity on an abiotic surface, the biofilms submitted to the treatments were detached from the plate and the microorganisms were submitted to the same procedures as those described previously for the development of the biofilms [16]. After biofilm formation, quantification of colonies $(\mathrm{CFU} / \mathrm{mL})$, evaluation of cell metabolism

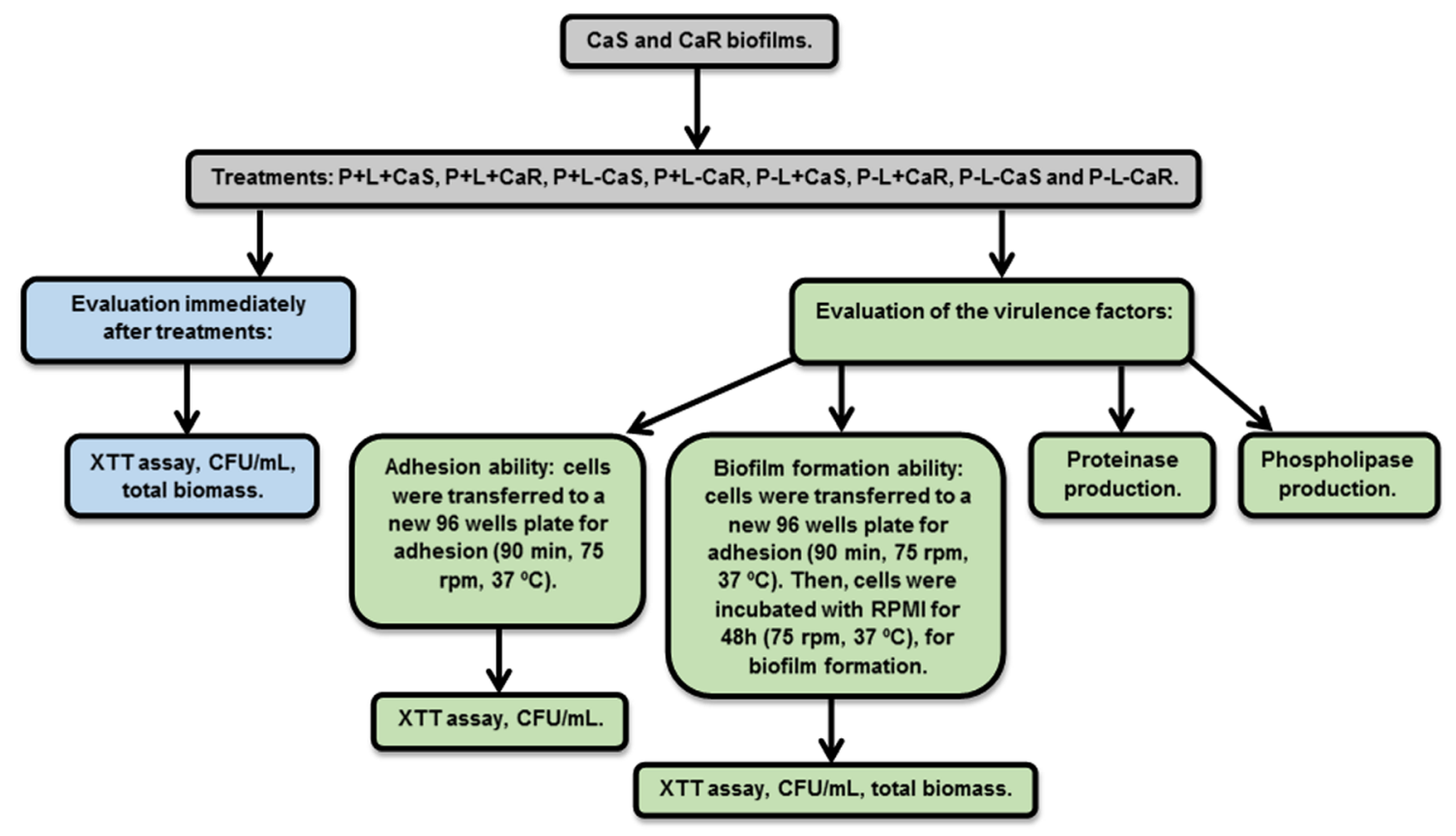

Fig. 1 Flowchart of the methods used for evaluation of the treatments and the virulence factors after the treatments 
(XTT), and total biomass were performed. The values obtained after biofilm formation were statistically compared with those obtained from biofilms immediately after aPDT.

The capacity for phospholipase and proteinase synthesis was evaluated by means of a fluorimetric test. To measure the phospholipase production after aPDT, the biofilms were resuspended in $200 \mu \mathrm{L}$ of lysis buffer and sonicated for $20 \mathrm{~s}$. The biofilms were removed from the bottom of the culture plate wells with the aid of a pointer, transferred to Eppendorf tubes, and centrifuged $(10,000 \mathrm{rpm} / 5 \mathrm{~min})$. The Amplex® Red Phosphatidylcholine-Specific Phospholipase C Assay Kit (\#A-12218) was used, in accordance with the manufacturer's instructions. The assays were performed in black 96well plates in a total volume of $200 \mu \mathrm{L}$ per well $(100 \mu \mathrm{L}$ of the centrifugation product of the biofilms and $100 \mu \mathrm{L}$ of the working solution). Fluorescence was read in the fluorescence microplate reader (Fluoroskan Ascent MicroplateTM, USA) at 544-nm excitation and 590-nm emission. The fluorescence values (in nanometers) were recorded and used for comparisons with the fluorescence values of the positive controls provided by the manufacturer (purified PL-C from Bacillus cereus and hydrogen peroxide) [20].

To evaluate proteinase enzyme production, after performing the proposed treatments, $200 \mu \mathrm{L}$ of RPMI medium was added in each orifice of the samples. After $24 \mathrm{~h}$ of incubation at $37^{\circ} \mathrm{C}$ under agitation $(75 \mathrm{rpm})$, the biofilms were removed from inside the wells with the aid of a pointer, transferred to Eppendorf tubes, and centrifuged at 10,000 rpm for $5 \mathrm{~min}$. To evaluate proteinase secretion, the EnzChek ${ }^{\circledR}$ Protease Assay Kit (\#E-6638) was used, in accordance with the manufacturer's instructions. The assays were performed in black 96-well plates in a total volume of $200 \mu \mathrm{L}$ per well $(100 \mu \mathrm{L}$ of the centrifugation product of the biofilms and $100 \mu \mathrm{L}$ of the working solution). Fluorescence readout was obtained in Fluoroskan at 485-nm excitation and 538-nm emission. The fluorescence values were used in linear equations derived from the standard curves obtained from trypsin solutions, and the enzymatic activity was expressed in nanograms per milliliter [20].

\section{Statistical analysis}

Homogeneity of variance and normality of the data were verified by the Levene and Shapiro-Wilk tests, respectively. The results of biofilm adhesion and formation were analyzed statistically by means of three-way analysis of variance (ANOVA): time (immediately after treatments and after biofilm adhesion or formation subsequently to aPDT), strain (susceptible and resistant), and treatment groups $(\mathrm{P}-\mathrm{L}-, \mathrm{P}+\mathrm{L}-, \mathrm{P}-\mathrm{L}+$, and $\mathrm{P}+\mathrm{L}+$ ). For multiple comparisons, the post hoc Tukey test was used for homoscedastic data and the Games-Howell test for heteroscedastic data. On the other hand, when the assumption of normality was not found, data were ranked and non- parametric analysis (ANOVA on rank) and the Games-Howell post hoc test were used. The proteinase and phospholipase data were analyzed by two-way ANOVA and the Tukey post hoc test for homoscedastic data and the Games-Howell test for heteroscedastic data. The level of significance adopted was $5 \%(\alpha=0.05)$. Pearson's correlation between enzymatic production (proteinase and phospholipase) and the $\log _{10}(\mathrm{CFU} /$ $\mathrm{mL}$ ) values was also performed $(\alpha=0.01)$. These analyses were performed using the software SPSS (IBM® SPSS $®$ Statistics, version 20, Chicago, IL, USA).

\section{Results}

\section{Capacity for adhesion to the abiotic surface}

Regarding the quantification of colonies $(\mathrm{CFU} / \mathrm{mL})$, the biofilms presented immediately after aPDT a reduction in the viability of 19.09 and $18.7 \%$, equivalent to $1.20 \log _{10}$ and $1.14 \log _{10}$ compared with the control groups $(\mathrm{P}-\mathrm{L}$ $-\mathrm{CaS}$ or $\mathrm{P}-\mathrm{L}-\mathrm{CaR}$ ) for $\mathrm{CaS}$ and $\mathrm{CaR}$, respectively. In general, it was observed that all the cells submitted to the treatments presented reduced capacity for adhesion. Comparing the groups at the times evaluated (immediately after treatments and after adhesion subsequently to aPDT), $68.9 \%$ of the cells in the $\mathrm{P}-\mathrm{L}-\mathrm{CaS}$ group adhered to the polystyrene plate, while $63 \%$ of the cells in the $\mathrm{P}+\mathrm{L}+\mathrm{CaS}$ group presented capacity for adherence. For $\mathrm{CaR}, 74.2 \%$ of the cells in the $\mathrm{P}-\mathrm{L}-\mathrm{CaS}$ group adhered to the polystyrene plate, and $73.9 \%$ of the cells in the $\mathrm{P}+\mathrm{L}+\mathrm{CaS}$ group presented capacity of adherence. Three-way analysis of variance revealed that there was no interaction among the three factors evaluated: strain, time, and treatment groups $(p=0.503)$. However, significant interaction was demonstrated between the factors "strain" and "time" $(p<0.001)$; for this reason, the Tukey post hoc test was used since the data showed normal distribution (Shapiro-Wilk test: $p \geq 0.05$ ) and were homoscedastic (Levene test: $p<0.001$ ). The Tukey post hoc test demonstrated a significant difference between the time intervals evaluated and similarity between the strains studied. Moreover, the factors "group" and "strain" were not significant for the capacity for adhesion, and only the factor time showed significant influence on the capacity for adhesion of the cells (Fig. 2).

Analysis of the XTT assay showed that the biofilms submitted to aPDT demonstrated reductions of 79.5 and $50.4 \%$ in metabolic activity for $\mathrm{CaS}$ and $\mathrm{CaR}$, respectively, in comparison with the control groups ( $\mathrm{P}-\mathrm{L}-\mathrm{CaS}$ or $\mathrm{P}-\mathrm{L}-\mathrm{CaR}$; Fig. 3 ). Subsequently, after aPDT, the capacity for adhesion of the viable cells was also evaluated by the XTT assay. When comparing the groups at the times evaluated (immediately after aPDT and after adhesion subsequently to aPDT), it was observed that adhesion of the cells reduced to $15.5 \%$ for the $\mathrm{P}-\mathrm{L}$ $-\mathrm{CaS}$ group, while for the $\mathrm{P}+\mathrm{L}+\mathrm{CaS}$ group the reduction was 
Fig. 2 Mean values and standard deviations of $\log _{10}(\mathrm{CFU} / \mathrm{mL})$ of $\mathrm{CaS}$ and $\mathrm{CaR}$ in the different time intervals of evaluation ( $I$ immediately after treatments, $A$ after adhesion), independent of the treatment groups $(n=36)$. Equal letters denote statistical similarity between the factors evaluated $(p>0.05)$

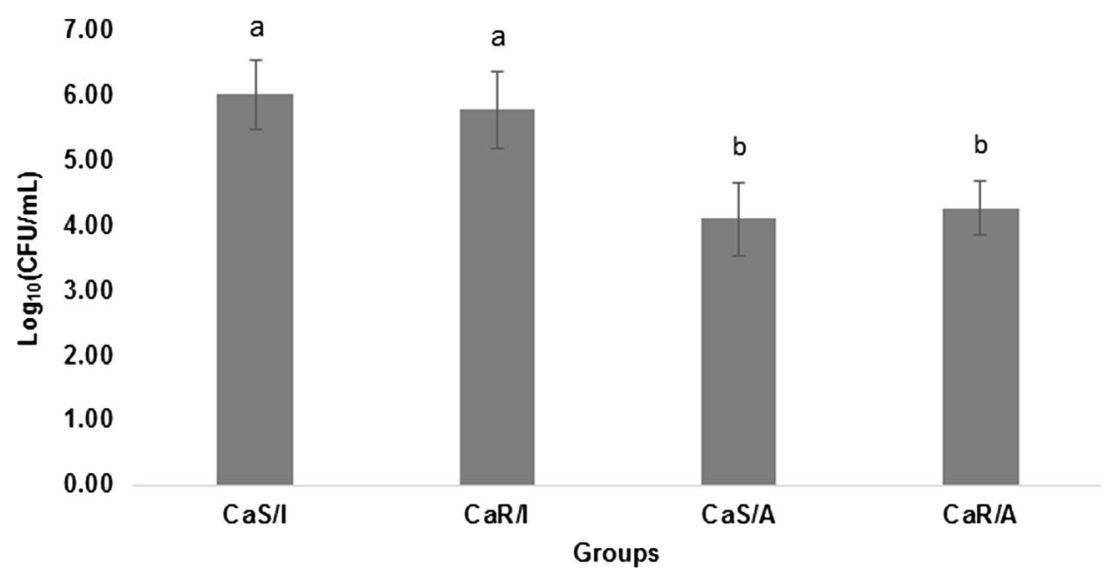

equivalent to $15.8 \%$. For the CaR strain, $19 \%$ of the cells in the $\mathrm{P}-\mathrm{L}-\mathrm{CaR}$ group were metabolically active, and for the $\mathrm{P}+$ $\mathrm{L}+\mathrm{CaR}$ group the metabolic activity reduced to $13 \%$. Threeway analysis of variance revealed significant interaction among the three factors evaluated $(p<0.001)$. Therefore, the multiple comparisons test of Games-Howell was applied since the data showed a normal distribution (Shapiro-Wilk test: $p \geq$ $0.64)$, but was heteroscedastic (Levene test: $p<0.001)$. The Games-Howell test demonstrated that the adhesion capacity for all groups of the $\mathrm{CaS}$ strain was significant different $(p<0.05)$ from that observed for the groups of the CaR strain. Time was also a significant factor $(p<0.05)$ since a reduction in the metabolic activity of the adhered cells was observed for all the groups evaluated (controls and aPDT). Moreover, the groups treated with aPDT showed significant difference $(p<0.001)$ compared with the other groups $(\mathrm{P}-\mathrm{L}-, \mathrm{P}+\mathrm{L}-$, and $\mathrm{P}-\mathrm{L}+)$, which did not show significant differences among them $(p>0.05)$.

\section{Capacity for biofilm formation on abiotic surface}

The quantification of colonies demonstrated reductions of 16.18 and $13.5 \%$ of the biofilms submitted to aPDT compared with the control group ( $\mathrm{P}-\mathrm{L}-\mathrm{CaS}$ or $\mathrm{P}-\mathrm{L}-\mathrm{CaR})$, equivalent to $1.01 \log _{10}$ and $0.81 \log _{10}$ for $\mathrm{CaS}$ and $\mathrm{CaR}$, respectively. When comparing the groups at the times evaluated (immediately after aPDT and after biofilm formation), $100 \%$ of the cells from the $\mathrm{P}-\mathrm{L}-\mathrm{CaS}$ and $\mathrm{P}+\mathrm{L}+\mathrm{CaS}$ groups were able to form biofilms. For CaR, 96.2 and $94.3 \%$ of the cells from the $\mathrm{P}-\mathrm{L}-\mathrm{CaS}$ and $\mathrm{P}+\mathrm{L}+\mathrm{CaS}$ groups, respectively, formed biofilms on the polystyrene plate. Three-way analysis of variance revealed that there was no significant interaction $(p=0.466)$ among the three factors evaluated: strain, time, and treatment groups. However, a significant interaction $(p<0.001)$ was found between group versus strain (Fig. 4) and time versus strain (Fig. 5). The Games-Howell post hoc test was used to evaluate the interaction between group $\times$ strain since the data showed normal distribution (Shapiro-Wilk test: $p>=0.074$ ) and was heteroscedastic (Levene test: $p=0.017)$. The Games-Howell test showed that the aPDT groups ( $\mathrm{CaS}$ and $\mathrm{CaR})$ were significantly different $(p<0.001)$ from the other groups $(\mathrm{P}-\mathrm{L}-, \mathrm{P}-\mathrm{L}+$, and $\mathrm{P}+\mathrm{L}-)$, which showed no significant difference $(p>0.487$ ) among them (Fig. 4). Furthermore, the Tukey post hoc test used to analyze the interaction between strain $x$ time (homoscedastic data, Levene test: $p=0.136$ ) demonstrated for CaR a significantly $(p \leq 0.007)$ reduced ability to form biofilms (Fig. 5).
Fig. 3 Mean values and standard deviations of the metabolic activity of the experimental groups for the two C. albicans strains evaluated immediately after application of the treatments and after the cell adhesion $(n=9)$

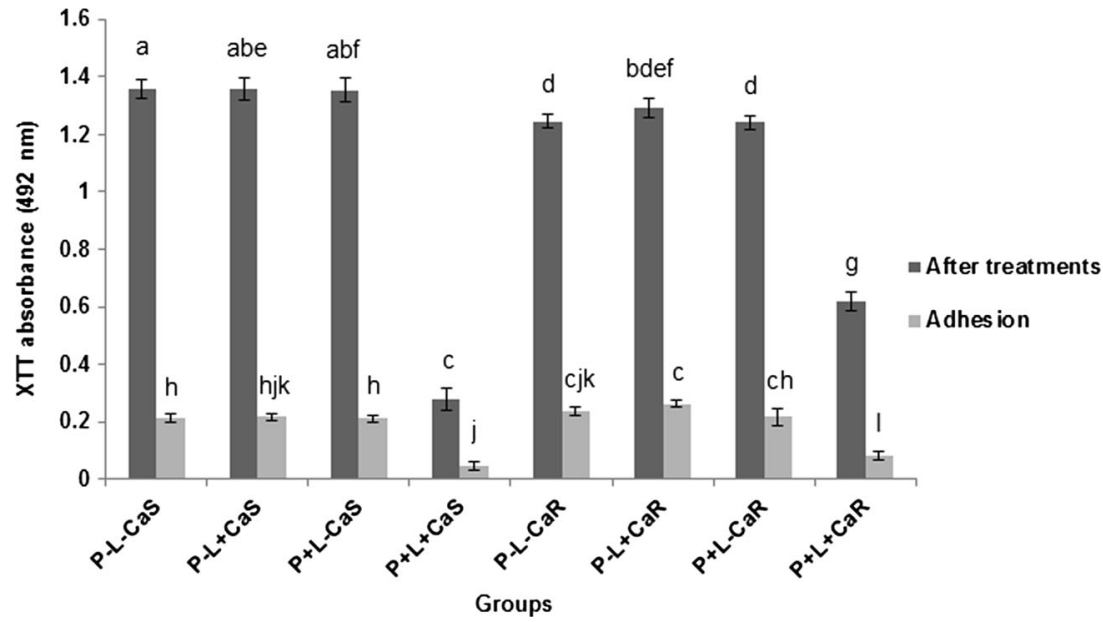


Fig. 4 Mean values and standard deviations of $\log _{10}(\mathrm{CFU} / \mathrm{mL})$ of the $\mathrm{CaS}$ and $\mathrm{CaR}$ strains from different groups (P-L-, $\mathrm{P}-\mathrm{L}+, \mathrm{P}+$ $\mathrm{L}-$, and $\mathrm{P}+\mathrm{L}+)$, independent of the time evaluated $(n=18)$. Equal letters denote statistical similarity between the factors evaluated $(p>0.05)$

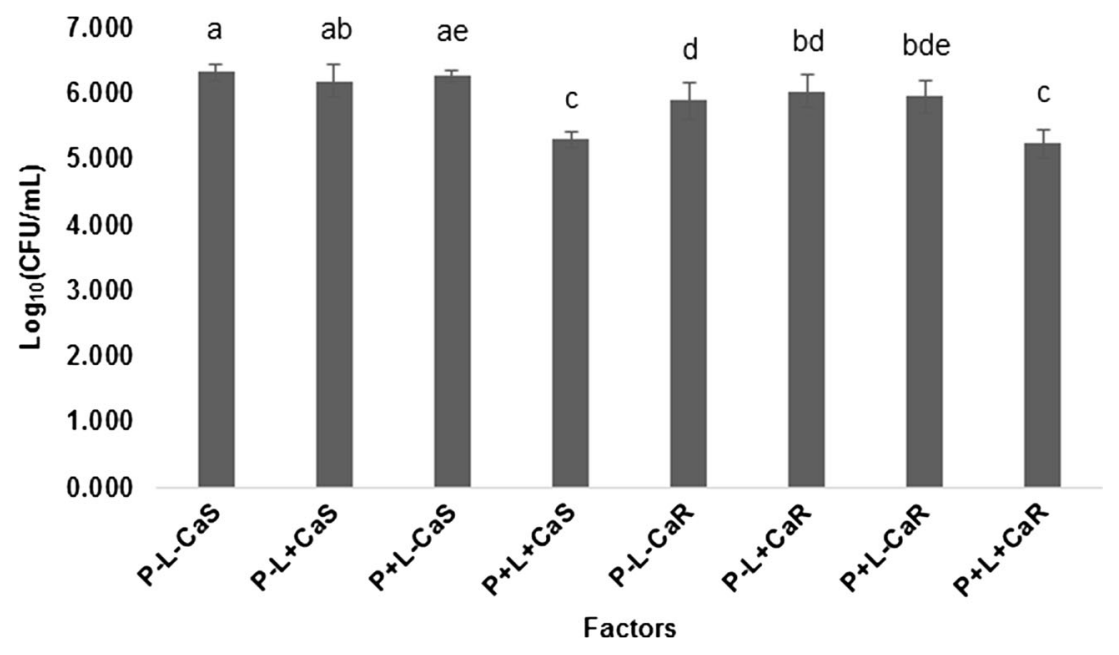

The result of the XTT assay demonstrated that aPDT promoted reductions of 78.23 and $39.1 \%$ in the metabolic activity of the $\mathrm{CaS}$ and $\mathrm{CaR}$ strains, respectively (Fig. 6).

After aPDT, the biofilm formation ability of the viable cells was also evaluated by the XTT assay. In general, it was observed that only the CaR strain submitted to the treatments presented a reduction in the metabolic activity. When comparing the groups at the times evaluated (immediately after aPDT and after biofilm formation subsequently to aPDT), it was observed that $56 \%$ of the cells from the $\mathrm{P}-\mathrm{L}-\mathrm{CaS}$ group were able to grow and form biofilms, while for the $\mathrm{P}+\mathrm{L}+\mathrm{CaS}$ group, this value was equivalent to $250 \%$, indicating that after aPDT the CaS presented an elevated ability for multiplication and biofilm formation. For $\mathrm{CaR}, 61.7$ and $67.2 \%$ of the cells from the $\mathrm{P}-\mathrm{L}-\mathrm{CaR}$ and $\mathrm{P}+\mathrm{L}+\mathrm{CaR}$ groups grew as biofilms (Fig. 6). Since the assumption of normality was not found (Shapiro-Wilk test: $p \leq 0.021$ ), a non-parametric analysis was used (ANOVA on rank). The non-parametric test revealed a significant interaction $(p<0.001)$ among the three criteria evaluated (time, strain, and groups). Additionally, the homogeneity of variance and normality of the rank values were assessed by Levene and Shapiro-Wilk tests, respectively.
According to these tests, the rank values showed a normal distribution $(p<0.05)$; however, they were heteroscedastic $(p<0.001)$. For this reason, the Games-Howell post hoc test was applied. The Games-Howell test revealed that, for $\mathrm{CaS}$, immediately after application of the treatment, there was a significant difference $(p \leq 0.028)$ between the group treated with aPDT and the other groups, which were similar ( $p \geq$ 0.929). For CaR, immediately after application of the treatment, there was a significant difference $(p \leq 0.017)$ between the group treated with aPDT and the other groups, with exception of the $\mathrm{P}+\mathrm{L}-$ group $(p=0.558)$. The groups $\mathrm{P}-\mathrm{L}-, \mathrm{P}+$ $\mathrm{L}-$, and $\mathrm{P}-\mathrm{L}+$ were similar $(p \geq 0.076)$. However, the biofilm formation ability was statistically similar among all the groups, demonstrating that aPDT was not able to reduce the ability of the two strains $(p=1.00$ for $\mathrm{CaS}$ and $p \geq 0.220$ for $\mathrm{CaR})$ to grow as biofilms. A significant difference $(p=0.002)$ between $\mathrm{CaR}$ and $\mathrm{CaS}$ strains immediately after aPDT was also verified, but after biofilm formation both strains were similar ( $p \geq 0.057$ ), independent of the group.

Finally, the crystal violet assay demonstrated that immediately after aPDT, the CaS strain demonstrated no reduction in total biomass compared with the other groups, while the
Fig. 5 Mean values and standard deviations of $\log _{10}(\mathrm{CFU} / \mathrm{mL})$ of $\mathrm{CaS}$ and $\mathrm{CaR}$ at different time intervals of evaluation $(I$ immediately after treatments, $A$ after biofilm formation), independent of the treatment group $(n=36)$. Equal letters denote statistical similarity between the factors evaluated $(p>0.05)$

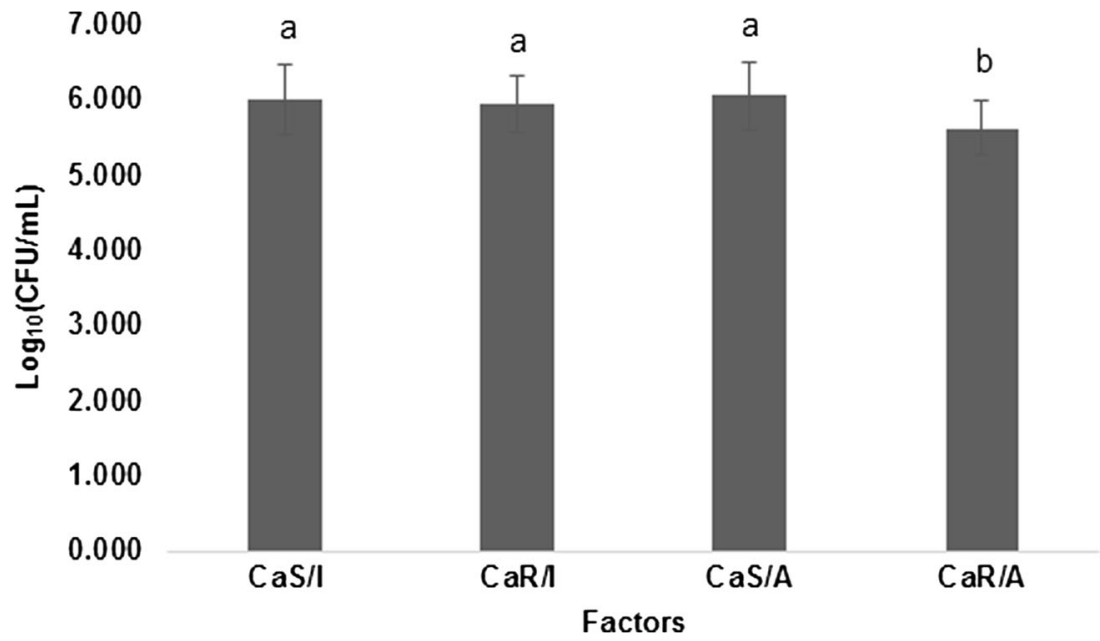




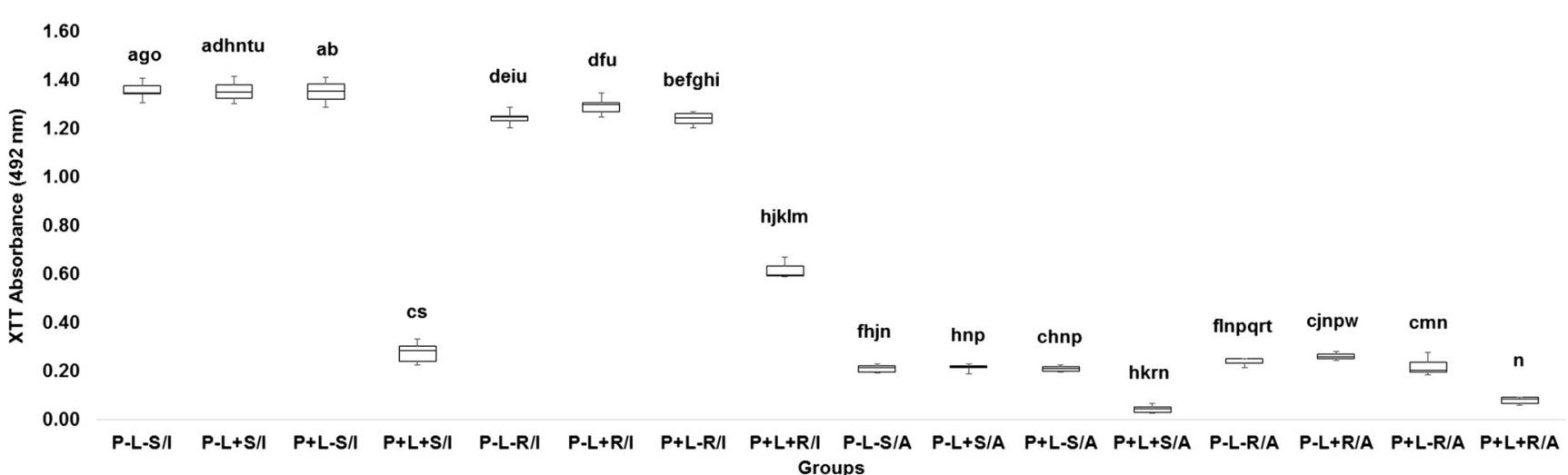

Fig. 6 Summary of XTT absorbance values of the two strains of $C$. albicans evaluated ( $S$ susceptible, $R$ resistant) at different time intervals ( $I$ immediately after treatments, $A$ after biofilm formation). The box plot shows the median (small filled squares), the first and third quartiles (outer edges of box), and the minimum and maximum values (error bars). A non-parametric analysis (ANOVA on rank) and the Games-Howell post hoc test were used. Equal letters denote statistical similarity between the factors evaluated $(p>0.05)$ resistant strain $(\mathrm{P}+\mathrm{L}+\mathrm{CaR})$ showed a reduction of $23.1 \%$ in the total biomass compared with the control ( $\mathrm{P}-\mathrm{L}-\mathrm{CaR}$; Fig. 7). After application of the treatments, the total biomass of the viable cells grown as biofilms was also quantified by crystal violet stain. It was observed that the total biomass values after treatments of all groups were lower than the initial values, showing that even the biofilms of the control group presented lower total biomass values (Fig. 7). When comparing the groups at the times evaluated (immediately after aPDT and after biofilm formation), reductions of 32.8 and $32.1 \%$ in the total biomass were observed for the $\mathrm{P}-\mathrm{L}-\mathrm{CaS}$ and $\mathrm{P}+\mathrm{L}+\mathrm{CaS}$ groups, respectively. For the $\mathrm{CaR}$ strain, a reduction of $49.5 \%$ in the total biomass was observed for the $\mathrm{P}-\mathrm{L}-\mathrm{CaR}$ group, while for the $\mathrm{P}+\mathrm{L}+\mathrm{CaR}$ group the biomass reduction was equivalent to $32.5 \%$. Three-way analysis of variance revealed a significant interaction $(p<0.001)$ among the three criteria evaluated: strain, time, and treatment groups. The Games-Howell post hoc test was applied since data showed normal distribution (Shapiro-Wilk: $p>=0.070$ ), but not homogeneity of variance (Levene test: $p<0.001$ ). The Games-
Howell test demonstrated for the $\mathrm{CaS}$ strain no significant difference $(p=1.000)$ between aPDT ( $\mathrm{P}+\mathrm{L}+\mathrm{CaS}$ group) and the other groups immediately after application of the treatments. After biofilm formation, subsequently to the treatments, the total biomass of all groups remained similar $(p \geq 0.984)$. The total biomass of the CaS biofilm was significantly lower $(p<0.001)$ than the initial value, demonstrating that even the biofilms of the control group showed lower total biomass values. For the CaR strain, immediately after aPDT, a significant reduction $(p \leq 0.028)$ in the total biomass of the biofilm submitted to aPDT $(\mathrm{P}+\mathrm{L}+\mathrm{CaR})$ was observed compared with the control and $\mathrm{P}+\mathrm{L}-$ groups. However, after biofilm formation, subsequently to the treatments, the biomasses of all groups were similar ( $p \geq 0.995$ ), showing that aPDT was not able to reduce the biofilm formation ability. It was also verified that, after receiving some type of treatment, the biomass value of the CaR biofilm was lower than the initial value $(p<0.001)$. Lastly, a significant difference $(p<0.001)$ was also observed between the $\mathrm{CaS}$ and $\mathrm{CaR}$ strains both immediately after application of the treatments and after biofilm formation.
Fig. 7 Mean values and standard deviations of total biomass of the experimental groups for both C. albicans strains evaluated immediately after application of the treatments and after biofilm formation $(n=9)$. Equal letters denote statistical similarity between the factors evaluated $(p>0.05)$

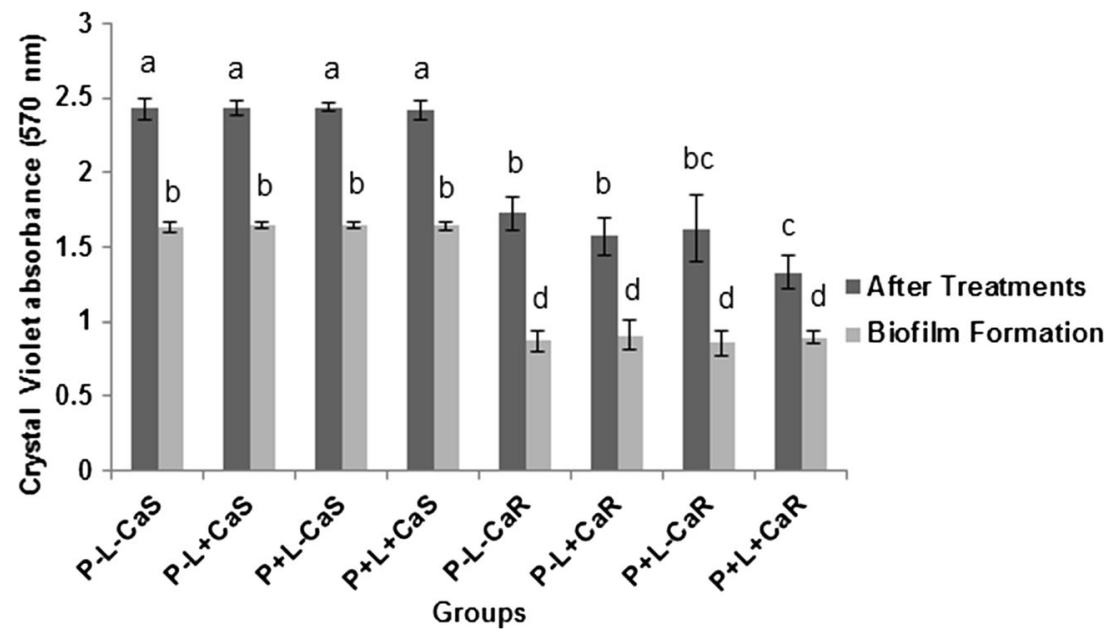




\section{Proteinase production}

The fluorescence values obtained in the readouts were normalized in accordance with the standard curve and the control reagents (Tris- $\mathrm{HCl}$ buffer and RPMI), and the value of proteinase production was obtained in the scale of nanograms per milliliter (Fig. 8). Two-way analysis of variance was applied, once there were two factors involved: strain and treatment. This test demonstrated a significant interaction $(p<0.001)$ between the two factors. For this reason, the Games-Howell post hoc test was used (normal distribution, Shapiro-Wilk test: $p>=0.061$; heterogeneity of variance, Levene test: $p<0.001$ ) and demonstrated that, for the $\mathrm{CaS}$ strain, only the $\mathrm{P}+\mathrm{L}-\mathrm{CaS}$ and $\mathrm{P}-\mathrm{L}+\mathrm{CaS}$ groups were similar $(p=0.995)$ and the others were significantly different $(p<0.001)$. For the $\mathrm{CaR}$ strain, no significant difference was observed between the $\mathrm{P}+\mathrm{L}-\mathrm{CaR}$ and $\mathrm{P}-\mathrm{L}+\mathrm{CaR}$ groups $(p=0.965)$ and the $\mathrm{P}-\mathrm{L}+\mathrm{CaR}$ and $\mathrm{P}+$ $\mathrm{L}+\mathrm{CaR}$ groups $(p=0.066)$, while the other groups showed significant difference $(p \leq 0.001)$ among them. A significant difference $(p<0.001)$ in proteinase production between the strains evaluated was also observed, with the resistant strain producing significantly less proteinase than the susceptible strain $(p<0.001)$. In addition, Pearson's correlation demonstrated a significant $(p=0.007)$ and positive correlation between the enzyme production and the values of $\log _{10}(\mathrm{CFU} /$ $\mathrm{mL} ; r=0.315)$, which means that the production of this enzyme was influenced by the quantity of viable cells.

\section{Phospholipase production}

The results of proteinase production were also analyzed by two-way analysis of variance, once there were two factors involved: strain and treatment. Two-way analysis of variance showed a significant interaction between the factors group and strain $(p<0.001)$. Tukey's post hoc test was applied (normal distribution, Shapiro-Wilk test: $p>=0.156$; homogeneity of variance, Levene test: $p=0.470$ ) and demonstrated that, for the $\mathrm{CaS}$, all groups differed among them and between the groups of the CaR $(p<0.001)$. For the CaR strain, a significant difference was observed only between the $\mathrm{P}+\mathrm{L}+\mathrm{CaR}$ and $\mathrm{P}-\mathrm{L}-\mathrm{CaR}$ groups $(p=0.002)$ and the $\mathrm{P}+\mathrm{L}+\mathrm{CaR}$ and $\mathrm{P}-\mathrm{L}+$ $\mathrm{CaR}$ groups, in addition to all the groups of the $\mathrm{CaS}$ (Fig. 9). It was also observed that there was a significant difference $(p=0.026)$ in phospholipase production between the strains evaluated, with the resistant strain producing significantly less of this enzyme than the susceptible strain $(p<0.001)$. In the same way as for proteinase, a significant $(p=0.004)$ and positive correlation between the enzyme production and the values of $\log _{10}(\mathrm{CFU} / \mathrm{mL})(r=0.338)$ was also observed, which means that the production of this enzyme was influenced by the quantity of viable cells.

\section{Discussion}

C. albicans expresses diverse virulence factors that contribute to its pathogenicity, such as polymorphism, the capacity for adhesion and biofilm formation, and degradative enzyme secretion [21]. The free radicals and singlet oxygen produced during aPDT may interact with diverse cell structures of the microorganisms (proteins, lipid membranes, and nucleic acids), resulting in cell death by apoptosis or necrosis [22]. Furthermore, there are reports that ROS generated during aPDT application may change the virulence profile of fungi $[23,24]$. Therefore, the aim of this study was to evaluate the expression of virulence factors of fluconazole-susceptible and fluconazole-resistant $C$. albicans after the aPDT mediated by PDZ in association with LED light.

In the present study, it was observed that immediately after application of the treatments, the biofilms submitted to aPDT demonstrated reductions of 79.5 and $50.4 \%$ in metabolic activity for $\mathrm{CaS}$ and $\mathrm{CaR}$, respectively. This finding is in
Fig. 8 Mean values and standard deviations of proteinase production (in nanograms per milliliter) of the experimental groups for both $C$. albicans strains evaluated. Equal letters denote statistical similarity $(p>0.05)$

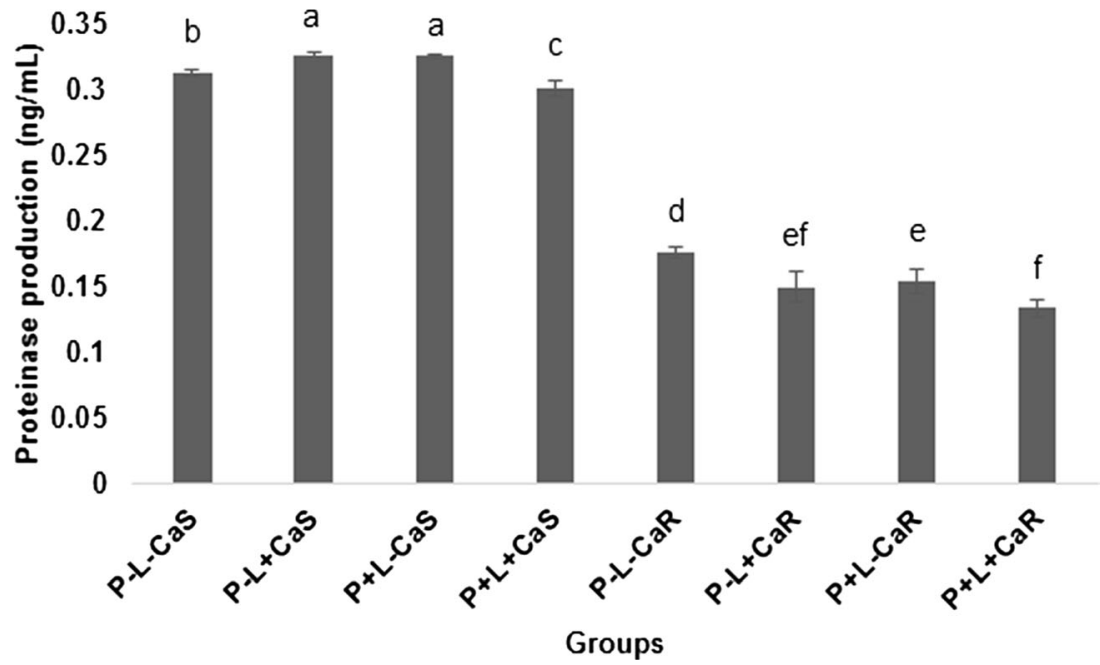


Fig. 9 Mean values and standard deviations of phospholipase production (in nanograms per milliliter) of the experimental groups for both $C$. albicans strains evaluated. Equal letters indicate statistical similarity $(p>0.05)$

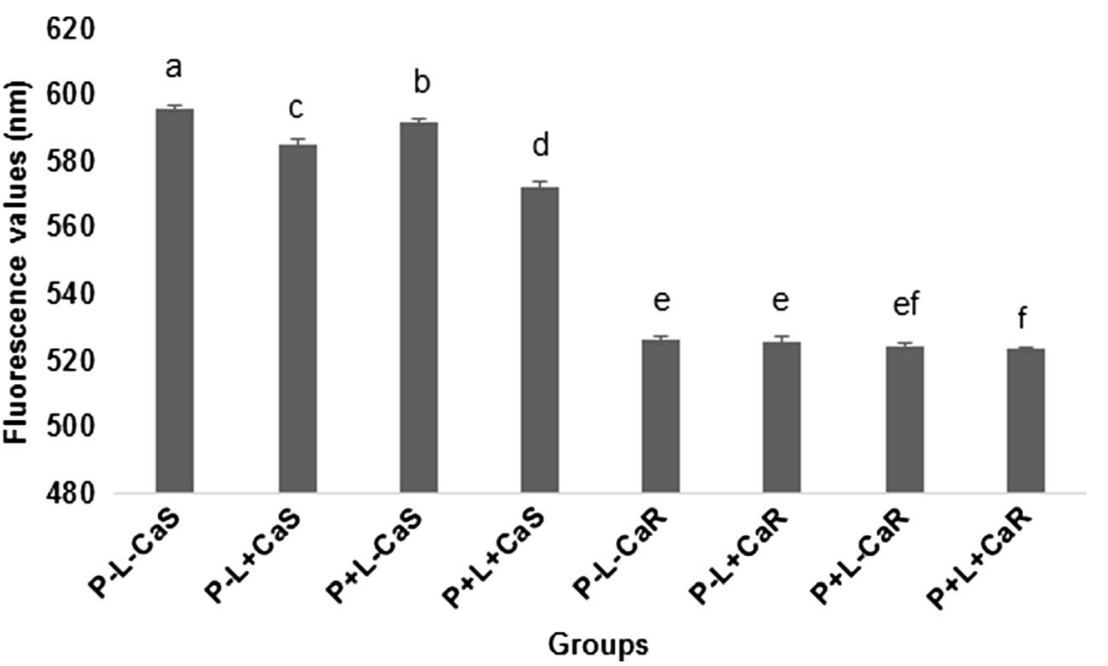

agreement with those found in the literature in studies that evaluated the photoactivation of strains of Candida by using PDZ as PS; however, it is important to point out that these studies did not evaluate fluconazole-resistant strains. Dovigo et al. [16] verified that aPDT mediated by PDZ associated with LED light reduced the metabolic activity of clinical isolated biofilms of C. albicans, C. tropicalis, and C. glabrata by $62.1,76.0$, and $76.9 \%$, respectively. In the study conducted by Quishida et al. [17], the multispecies biofilms of C. albicans, C. glabrata, and Streptococcus mutans incubated with PDZ $(100,150,175$, or $200 \mathrm{mg} / \mathrm{L})$ and irradiated with LED light $\left(37.5 \mathrm{Jcm}^{2}\right)$ presented $36 \%$ of reduction in metabolic activity when compared with the control group.

With regard to the colony quantification test $(\mathrm{CFU} / \mathrm{mL})$ in the present study, it was observed that immediately after aPDT, compared with the control group ( $\mathrm{P}-\mathrm{L}-\mathrm{CaS}$ or $\mathrm{P}-\mathrm{L}$ $-\mathrm{CaR})$, the biofilms submitted to aPDT presented reductions equivalent to 1.20 and $1.14 \log _{10}$ for $\mathrm{CaS}$ and $\mathrm{CaR}$, respectively. These results are promising since the patterns of inactivation observed for the susceptible and resistant strains were similar. Studies have demonstrated that aPDT promoted the inactivation of suspensions of fluconazole-resistant C. albicans; however, different PSs were used. Paz-Cristobal et al. [25] evaluated the effectiveness of aPDT, mediated by hypericin or dimethylmethylene blue, for the inactivation of suspensions of clinical isolates of $\mathrm{CaS}$ and $\mathrm{CaR}$ and observed complete inactivation of the suspensions. In the study conducted by Chien et al. [26], chitosan was used to enhance the efficiency of aPDT (mediated by toluidine blue) against clinical isolates of $\mathrm{CaS}$ and $\mathrm{CaR}$, and they demonstrated that 30 min of incubation with chitosan combined with aPDT promoted photoinactivation of the strains in suspension. Mang et al. [27] demonstrated that suspensions of clinical isolates of antifungal-resistant Candida spp. presented susceptibility to aPDT mediated by Photofrin similar to a reference strain.

In the study of Dovigo et al. [13], suspensions and biofilms of resistant and standard strains of $C$. albicans and C. glabrata were treated with Photogem, followed by irradiation with LED light. It was observed that the effectiveness of aPDT was dependent on the species, and the resistant strains were less susceptible to the effects of aPDT. The authors also observed that the strains organized as biofilms were less susceptible to aPDT. In general, these studies demonstrated that aPDT has the capacity for inactivating $C$. albicans in suspension; however, complete inactivation of this yeast organized as biofilm continues to be an important challenge.

The capacity for adhesion of both strains was evaluated after the application of the aPDT treatments, by means of the XTT and CFU/mL tests. The adhesion of the microorganisms to biotic or abiotic surfaces is the first step of colonization and subsequent infection, and therefore, adhesion is considered an important virulence factor [28]. According to the pertinent literature, this is the first study that evaluated the capacity of adhesion of fluconazole-susceptible and fluconazole-resistant C. albicans to an abiotic surface after the application of aPDT. The results of the XTT assay demonstrated that aPDT reduced the capacity of adhesion of cells, and there was significant difference between $\mathrm{CaS}$ and CaR (only 15.8 and $13 \%$ of the $\mathrm{CaS}$ and $\mathrm{CaR}$, respectively, were capable of adhering to the polystyrene plates). However, the tendency of reduction observed in XTT was not observed in the CFU/mL counts since it was not possible to verify significant difference in the capacity for adhesion between the cells treated with aPDT in comparison with the other groups. These findings corroborate the results obtained by Soares et al., who evaluated the effect of aPDT mediated by toluidine blue on the capacity of adhesion of Candida species to bucco-epithelial cells (BECs) [23]. These authors observed that the greater the effectiveness of aPDT against the Candida species, the greater was the reduction in adhesion of the yeast to BECs. Two isolates of fluconazole-sensitive $C$. albicans presented elevated reduction in the number of viable cells (mean of $5.20 \log _{10}$ ), and the adhesion of these strains to the BECs was also significantly inhibited (mean reduction of $61.5 \%$ ). On the other hand, 
C. albicans isolate that presented the lowest reduction in cell viability (mean of $2.15 \log _{10}$ ) demonstrated lower inhibition for adhesion to BECs (mean reduction of $34.5 \%$ ). Furthermore, one application of aPDT reduced 3.54 and $1.95 \log _{10}$ of clinical isolates of fluconazole-resistant C. albicans and C. tropicalis, respectively, and adhesion to BECs was reduced by around 61 and $66 \%$, respectively. These authors suggested that the change in the capacity of adhesion might be the effect of aPDT on the cytoplasmic membrane of the Candida spp. cells [23].

Another virulence factor evaluated was the capacity of biofilm formation of $C$. albicans after aPDT. According to the results obtained in the colony quantification tests $(\mathrm{CFU} / \mathrm{mL})$, aPDT was capable of reducing the capacity of both strains of C. albicans to form biofilms (16.1 and $13.5 \%$ for the $\mathrm{P}+\mathrm{L}+$ $\mathrm{CaS}$ and $\mathrm{P}+\mathrm{L}+\mathrm{CaR}$ groups, respectively). Moreover, the $\mathrm{CaR}$ strain presented lower biofilm formation ability in comparison with the CaS strain. This result is in agreement with the study conducted by Rosseti et al., who also observed that aPDT, mediated by toluidine blue, reduced the capacity of $\mathrm{C}$. albicans to form biofilms [29]. Furthermore, the authors demonstrated that aPDT promoted an increase in ROS production and cell permeability. According to the authors, ROS production and the increase in cell permeability caused by aPDT were responsible for inhibiting the cell proliferation and formation of biofilms. Therefore, it could be suggested that cells that survive aPDT are more susceptible to future treatments.

Another important factor that must be observed is the result obtained in the total biomass test, by means of crystal violet staining. Immediately after application of the treatments, aPDT reduced the total biomass of CaR by $23.1 \%$ in comparison with the control, and there was no reduction in the biomass of CaS. After application of the treatments, the surviving cells were submitted to the procedures of biofilm formation and total biomass was measured again; no difference was verified between the strains that received treatments with aPDT and their respective control groups. However, it is important to point out that the total biomass value of the $\mathrm{CaS}$ was higher in all the periods evaluated in comparison to the values of the $\mathrm{CaR}$. These findings do not corroborate those found in the literature. Vavala et al. [30] characterized biofilms $(24,48$, and $72 \mathrm{~h}$ ) of clinical isolates of susceptible and resistant C. albicans and verified that the resistant strains presented $50 \%$ higher total biomass values than the susceptible strain. The differences between the results obtained in the these studies may be attributed to the $C$. albicans strain evaluated because, in the present study, reference strains (ATCC) were used, while Vavala et al. [30] evaluated clinical isolates.

The results of the present study also demonstrated that aPDT changed the capacity of both strains evaluated for secreting proteinase in comparison with the control group $(\mathrm{P}-\mathrm{L}-$ ). Moreover, CaR presented lower production of this enzyme in comparison with the $\mathrm{CaS}$. As regards phospholipase, it was also observed that the groups treated with aPDT differed statistically from the control groups and that the $\mathrm{CaR}$ presented lower ability to secrete this enzyme. However, a positive correlation between enzyme production and the values of $\log _{10}(\mathrm{CFU} / \mathrm{mL})(r=0.315$ for proteinase and $r=0.338$ for phospholipase) was observed, which means that the production of the enzymes was influenced by the quantity of viable cells. It is important to emphasize that, although the correlation coefficients of proteinase and phospholipase were positive and significant, the values obtained show a very weak correlation $(r=$ 0.3 ; for this reason, these results should be read carefully. These results partially corroborate the data obtained by Martins et al. [31], who evaluated the effects of aPDT on the capacity of $C$. albicans for producing phospholipase and proteinase in a murine model of oral candidosis when methylene blue was used in association with laser light. These authors observed the inhibitory effects of aPDT on the capacity of C. albicans to secrete proteinase; however, this treatment was not capable of reducing the secretion of phospholipase. The in vitro study conducted by Freire et al. [32] evaluated the effects of aPDT mediated by methylene blue and laser light on the expression of genes of $C$. albicans biofilms responsible for the enzymes proteinase (SAP5) and phospholipase (PLB2) by qPCR technique. The authors observed that aPDT was capable of reducing $60 \%$ of the expression of the SAP5 gene and $50 \%$ of the expression of the PLB2 gene in the samples; however, there was no significant difference when compared with the group of non-treated biofilms [32]. In addition to these enzymes produced by Candida, the activity of the lipase enzyme was also evaluated by Freire et al. [32] after the application of aPDT mediated by methylene blue. The cited authors observed that aPDT reduced by $50 \%$ the expression of the gene responsible for codifying this enzyme (LIP9) in C. albicans. However, it is important to evaluate whether the reduction in the enzyme production is not associated with the reduction of cell viability after aPDT. Therefore, in the present investigation, correlation between cell viability and enzyme production was performed and a positive correlation was shown.

The production of proteinase and phospholipase enzymes by $\mathrm{CaS}$ was greater in comparison with that of the $\mathrm{CaR}$. Some studies have shown an increase in the production of proteinase by $\mathrm{CaR}$ after the use of subinhibitory concentrations of amphotericin B. Kumar et al. [33] verified higher proteinase enzyme production in strains resistant to amphotericin B compared with susceptible strains. Similarly, studies have verified that phospholipase secretion by strains resistant to medications is higher [34, 35]. Our results do not corroborate those of these studies; all of these studies used clinical isolate strains of Candida spp., whereas in the present study a standard strain (ATCC) of fluconazole-resistant C. albicans was used. We can hypostasize that the resistance of the Candida strain evaluated in this study is not related to the 
virulence factors (proteinase and phospholipase); however, it could be associated with efflux pumps and other resistance mechanisms (ergosterol synthesis).

Apart from these virulence factors assessed in the present study, the effects of aPDT on the expression of other pathogenicity factors of $C$. albicans have been evaluated. The transition of $C$. albicans into hyphae is responsible for the invasion of this fungus into the epithelial tissue, favoring penetration and growth of this microorganism among epithelial cells. The germinative tube is the first stage of the morphological transition from blastopore to hypha [36]. Munin et al. [24] observed that aPDT mediated by methylene blue and laser light reduced the formation of C. albicans hyphae, whereas Kato et al. [37] observed that aPDT mediated by methylene blue inhibited the formation of germinative tubes; however, the authors considered this effect transitory since this alteration was not observed in the daughter cells. Other studies have also evaluated the effects of aPDT on virulence factors of bacteria [38-40]. aPDT mediated by toluidine blue reduced the activity of lipopolysaccharides and proteases of the Gram-negative bacteria Escherichia coli and Pseudomonas aeruginosa [38], as well as the activity of proteolytic enzymes of suspensions of Porphyromonas gingivalis [39]. Similarly, aPDT mediated by methylene blue was capable of inhibiting the activity of enzymes V8 protease, $\alpha$-hemolysin, and sphingomyelinase of Staphylococcus aureus [40].

\section{Conclusion}

Based on the results obtained in the present study, the authors could conclude that aPDT reduced the viability of both strains, fluconazole-susceptible and fluconazole-resistant $C$. albicans. However, regarding the virulence factors evaluated, it was demonstrated that aPDT did not alter the adherence and biofilm formation ability as well as enzymatic production.

Acknowledgements We thank the Physics Institute of São Carlos (University of São Paulo, São Carlos, SP, Brazil) for designing the LED device used in the present investigation. The authors appreciate Prof. Dr. Livia Nordi Dovigo, Professor of Biostatistics, for the statistical instructions.

\section{Compliance with ethical standards}

Funding information This work was supported by São Paulo Research Foundation (FAPESP - grant nos. 2012/21201-1 and 2012/02942-0) and Centros de Pesquisa, Inovação e Difusão (CEPID grant no. 2013/07276-1). The funders had no role in the study design, data collection and analysis, decision to publish, or preparation of the manuscript.

Conflict of interest The authors declare that they have no conflict of interest.
Ethical approval This article does not contain any studies with human participants or animals performed by any of the authors. The authors have attested that for this type of study, formal consent is not required.

\section{References}

1. Eggimann P, Garbino J, Pittet D (2003) Epidemiology of Candida species infections in critically ill non-immunosuppressed patients. Lancet Infect Dis 3:685-702

2. Farah CS, Ashman RB, Challacombe SJ (2000) Oral candidosis. Clin Dermatol 18:553-562

3. Perezous LF, Flaitz CM, Goldschmidt ME, Engelmeier RL (2005) Colonization of Candida species in denture wearers with emphasis on HIV infection: a literature review. J Prosthet Dent 93:288-293

4. Ferreira C, Silva S, Faria-Oliveira F, Pinho E, Henriques M, Lucas $\mathrm{C}$ (2010) Candida albicans virulence and drug-resistance requires the $O$-acyltransferase Gup 1p. BMC Microbiol 10:238. doi:10.1186/ 1471-2180-10-238

5. Ramage G, Rajendran R, Sherry L, Williams C (2012) Fungal biofilm resistance. Int J Microbiol 2012:528521. doi:10.1155/2012/ 528521

6. Hube B, Naglik J (2001) Candida albicans proteinases: resolving the mystery of a gene family. Microbiology 147:1997-2005

7. Niewerth M, Korting HC (2001) Phospholipases of Candida albicans. Mycoses 44:361-367

8. Sardi JC, Scorzoni L, Bernardi T, Fusco-Almeida AM, Mendes Giannini MJ (2013) Candida species: current epidemiology, pathogenicity, biofilm formation, natural antifungal products and new therapeutic options. J Med Microbiol 62:10-24. doi:10.1099/jmm. $0.045054-0$

9. Hunter KD, Gibson J, Lockhart P, Pithie A, Bagg J (1998) Fluconazole-resistant Candida species in the oral flora of fluconazole-exposed HIV-positive patients. Oral Surg Oral Med Oral Pathol Oral Radiol Endod 85:558-564

10. White TC, Marr KA, Bowden RA (1998) Clinical, cellular, and molecular factors that contribute to antifungal drug resistance. Clin Microbiol Rev 11:382-402

11. Chandra J, Kuhn DM, Mukherjee PK, Hoyer LL, McCormick T, Ghannoum MA (2001) Biofilm formation by the fungal pathogen Candida albicans: development, architecture, and drug resistance. J Bacteriol 183:5385-5394

12. Bliss JM, Bigelow CE, Foster TH, Haidaris CG (2004) Susceptibility of Candida species to photodynamic effects of Photofrin. Antimicrob Agents Chemother 48:2000-2006

13. Dovigo LN, Pavarina AC, Mima EGO, Giampaolo ET, Vergani CE, Bagnato VS (2011) Fungicidal effect of photodynamic therapy against fluconazole-resistant Candida albicans and Candida glabrata. Mycoses 54:123-130. doi:10.1111/j.1439-0507.2009.01769.x

14. Mima EG, Pavarina AC, Dovigo LN, Vergani CE, Costa CAS, Kurashi C, Bagnato VS (2012) Susceptibility of Candida albicans to photodynamic therapy in a murine modelo of oral candidosis. Oral Surg Oral Med Oral Pathol Oral Radiol Endod 109:392-401. doi:10.1016/j.tripleo.2009.10.006

15. Ferreira J, Menezes PFC, Kurachi C, Sibata C, Allison RR, Bagnato VS (2008) Photostability of different chlorine photosensitizers. Laser Phys Lett 5:156-161

16. Dovigo LN, Carmello JC, Carvalho MT, Mima EG, Vergani CE, Bagnato VS, Pavarina AC (2013) Photodynamic inactivation of clinical isolates of Candida using Photodithazine ${ }^{\circledR}$. Biofouling 29:1057-1067. doi:10.1080/08927014.2013.827668

17. Quishida CC, Carmello JC, Mima EG, Bagnato VS, Machado AL, Pavarina AC (2015) Susceptibility of multispecies biofilm to 
photodynamic therapy using Photodithazine®. Lasers Med Sci 30: 2303-2312. doi:10.1007/s10103-013-1397-z

18. Lambrechts SA, Aalders MC, Verbraak FD, Lagerberg JW, Dankert JB, Schuitmaker JJ (2005) Effect of albumin on the photodynamic inactivation of microorganisms by a cationic porphyrin. $\mathrm{J}$ Photochem Photobiol B 79:51-57

19. Zamperini CA, Machado AL, Vergani CE, Pavarina AC, Giampaolo ET, da Cruz NC (2010) Adherence in vitro of Candida albicans to plasma treated acrylic resin. Effect of plasma parameters, surface roughness and salivary pellicle. Arch Oral Biol 55:763-770. doi:10.1016/j.archoralbio.2010.06.015

20. Sanitá PV, Zago CE, Mima EG, Pavarina AC, Jorge JH, Machado AL, Vergani CE (2014) In vitro evaluation of the enzymatic activity profile of non-albicans Candida species isolated from patients with oral candidiasis with or without diabetes. Oral Surg Oral Med Oral Pathol Oral Radiol 118:84-91. doi:10.1016/j.0ooo.2014.03.020

21. Calderone RA, Fonzi WA (2001) Virulence factors of Candida albicans. Trends Microbiol 9:327-335

22. Donnelly RF, McCarron PA, Tunney MM (2008) Antifungal photodynamic therapy. Microbiol Res 163:1-12

23. Soares BM, da Silva DL, Sousa GR, Amorim JC, de Resende MA, Pinotti M, Cisalpino PS (2009) In vitro photodynamic inactivation of Candida spp. growth and adhesion to buccal epithelial cells. J Photochem Photobiol B 94:65-70. doi:10.1016/j.jphotobiol.2008. 07.013

24. Munin E, Giroldo LM, Alves LP, Costa MS (2007) Study of tube formation by Candida albicans after photodynamic antimicrobial chemotherapy (PACT). J Photochem Photobiol B 88:16-20

25. Paz-Cristobal MP, Royo D, Rezusta A, Andrés-Ciriano E, Alejandre MC, Meis JF, Revillo MJ, Aspiroz C, Nonell S, Gilaberte Y (2014) Photodynamic fungicidal efficacy of hypericin and dimethyl methylene blue against azole-resistant Candida albicans strains. Mycoses 57:35-42. doi:10.1111/myc.12099

26. Chien HF, Chen CP, Chen YC, Chang PH, Tsai T, Chen CT (2013) The use of chitosan to enhance photodynamic inactivation against Candida albicans and its drug-resistant clinical isolates. Int J Mol Sci 14:7445-7456. doi:10.3390/ijms14047445

27. Mang TS, Mikulski L, Hall RE (2010) Photodynamic inactivation of normal and antifungal resistant Candida species. Photodiagnosis Photodyn Ther 7:98-105. doi:10.1016/j.pdpdt.2010.03.001

28. Modrzewska B, Kurnatowski P (2015) Adherence of Candida sp. to host tissues and cells as one of its pathogenicity features. Ann Parasitol 61:3-9

29. Rosseti IB, Chagas LR, Costa MS (2014) Photodynamic antimicrobial chemotherapy (PACT) inhibits biofilm formation by Candida albicans, increasing both ROS production and membrane permeability. Lasers Med Sci 29:1059-1064. doi:10.1007/s10103-0131473-4

30. Vavala E, Colone M, Passariello C, Celestino I, Toccacieli L, Stringaro A, Angiolella L (2013) Characterization of biofilms in drug-sensitive and drug-resistant strains of Candida albicans. J Chemother 25:87-95. doi:10.1179/1973947812Y.0000000047

31. Martins Jda S, Junqueira JC, Faria RL, Santiago NF, Rossoni RD, Colombo CE Jorge AO (2011) Antimicrobial photodynamic therapy in rat experimental candidiasis: evaluation of pathogenicity factors of Candida albicans. Oral Surg Oral Med Oral Pathol Oral Radiol Endod 111(1):71-77. doi:10.1016/j.tripleo.2010.08.012

32. Freire F, de Barros PP, da Silva ÁD, Brito GN, Junqueira JC, Jorge AO (2015) Evaluation of gene expression SAP5, LIP9, and PLB2 of Candida albicans biofilms after photodynamic inactivation. Lasers Med Sci 30:1511-1518. doi:10.1007/s10103-015-1747-0

33. Kumar R, Shukla PK (2010) Amphotericin B resistance leads to enhanced proteinase and phospholipase activity and reduced germ tube formation in Candida albicans. Fung Biol 114:189-197. doi: 10.1016/j.funbio.2009.12.003

34. Ying S, Chunyang L (2012) Correlation between phospholipase of Candida albicans and resistance to fluconazole. Mycoses 55:50 55. doi:10.1111/j.1439-0507.2011.02024.x

35. Furlaneto-Maia L, Specian AF, Bizerra FC, de Oliveira MT, Furlaneto MC (2008) In vitro evaluation of putative virulence attributes of oral isolates of Candida spp. obtained from elderly healthy individuals. Mycopathologia 166:209-217. doi:10.1007/s11046008-9139-7

36. Thompson DS, Carlisle PL, Kadosh D (2011) Coevolution of morphology and virulence in Candida species. Eukaryot Cell 10:11731182. doi:10.1128/EC.05085-11

37. Kato IT, Prates RA, Sabino CP, Fuchs BB, Tegos GP, Mylonakis E, Hamblin MR, Ribeiro MS (2013) Antimicrobial photodynamic inactivation inhibits Candida albicans virulence factors and reduces in vivo pathogenicity. Antimicrob Agents Chemother 57:445-451. doi:10.1128/AAC.01451-12

38. Kömerik N, Wilson M, Poole S (2000) The effect of photodynamic action on two virulence factors of Gram-negative bacteria. Photochem Photobiol 72:676-680

39. Packer S, Bhatti M, Burns T, Wilson M (2000) Inactivation of proteolytic enzymes from Porphyromonas gingivalis using lightactivated agents. Lasers Med Sci 15:24-30

40. Tubby S, Wilson M, Nair SP (2009) Inactivation of staphylococcal virulence factors using a light-activated antimicrobial agent. BMC Microbiol 9:211. doi:10.1186/1471-2180-9-211 